\title{
Clinical Phenotypes Associated With Preterm Births at Jaramogi Oginga Odinga Teaching and Referral Hospital in Kisumu County, Kenya
}

\author{
Juma, Edwin Omondi ${ }^{1}$, Prof. Margaret Keraka ${ }^{2}$, Dr. Anthony Wanyoro ${ }^{3}$ \\ ${ }^{1}$ Department of Population, Reproductive Health and Community Resource Management, \\ Kenyatta University \\ ${ }^{2}$ Dean School of Public Health and Applied Human Sciences, Kenyatta University \\ ${ }^{3}$ Department of Obstetrics and Gynecology, Kenyatta University
}

\begin{abstract}
Preterm birth is a global health problem. It is the leading cause of child and neonatal mortality globally including Kenya. Preterm birth is the birth occurring before 37 completed weeks of gestation. In Kenya, preterm birth is the leading cause of neonatal mortality as it contributes to $35 \%$ of deaths among the neonates while Kisumu County is among the county's leading with child under-five mortality rate at 133 deaths per 1000 live births. The main objective of this study was to identify the clinical phenotypes associated with preterm birth in JOOTRH in Kisumu County. It was a cross sectional study based on women who had a preterm birth alive or stillbirth at JOORTH in Kisumu County. Purposive sampling technique was used to select 178 respondents who met the inclusion criteria. Interviewer administered questionnaire was used to collect both qualitative and quantitative data. Data was analyzed by computer software SPSS version 23; descriptive statistics was used together with inferential statistics (Chi-square and Fisher's Exact test) to help in the identification of the statistical significance of any association between the variables. A $p$ value of $<0.05$ was used. Bivariate analysis was utilized to measure the strength of associations. Data presented by use of frequency tables and narrative description. Ethical clearance was sought from Kenyatta University Ethics and Review Committee, permit sought from NACOSTI, consent and assent from the respondents. Results showed that maternal age $(p=0.011)$ to be statistical significant with preterm births. Clinical phenotypes based on maternal, fetal and placental conditions; preeclampsialeclampsia $(p=0.016)$, extrauterine infections which includes malaria, UTI and HIV $(p=0.030)$, severe maternal conditions that includes DM, anaemia, cardiac disease, hypertension prior to pregnancy and TB $(p=0.001)$, multiple gestations $(p=0.013)$, fetal anomaly $(0.048)$, IUGR $(p=0.049)$, antepartum stillbirth $(p=0.046)$ and APH/early bleeding that include placenta previa and placenta abruption $(p=0.025)$ were all significantly associated with preterm births. On bivariate analysis between clinical phenotypes and preterm births, all except multiple gestation $(p=0.416)$ and APH $(p=0.660)$ remained statistically significant. All clinical phenotypes (maternal, fetal and placental conditions) were significantly associated with preterm births. All clinical phenotypes except multiple gestations and APH/early bleeding remained statistically significant after bivariate analysis. The study recommends the use of Barro's classifications system of clinical phenotypes to phenotype all preterm births in JOOTRH. Early identification of maternal, fetal and placental conditions identified in this study to be associated with preterm births by adopting Barros' phenotyping of preterm births as a strategy to help prevent the occurrence of PTBs and eventually reduce neonatal deaths and under-five mortality.
\end{abstract}

Keywords: Clinical Phenotypes, Preterm Births, Jaramogi Oginga Odinga Teaching and Referral Hospital 
DOI: 10.7176/ijcab.v3iIII.38, URN: nbn:de:0000ijcab.v3iIII.385

\section{Cite this Article:}

Juma, E., Keraka, M., \& Wanyoro, A. (2019). Clinical Phenotypes Associated With Preterm Births at Jaramogi Oginga Odinga Teaching and Referral Hospital in Kisumu County, Kenya. International Journal of Current Aspects, 3(III), 175-186. http://journals.ijcab.org/journals/index.php/ijcab/article/view/38

\section{INTRODUCTION}

Child mortality is the key indicator of child health, well-being and the cornerstone for tracking child survival set goals. The Millennium Development Goal (MDG) 4 target of reducing the child under-five mortality by two-third for the period that ended 2015 was missed globally including Kenya. This, despite the dropped in the child under-five mortality rate by 53 percent from 91 deaths per 1000 live births in 1990 to 43 deaths per 1000 live births in 2015 in the entire world (WHO, 2015b). On the other hand, the decline in neonatal mortality rate over the same period remained slower at 47 percent compared to 53 percent of under-five mortality. Neonatal period is a very critical period for child survival and neonatal mortality is increasingly becoming important because most of the child under-five mortality occurs during this period; it contributes to 40 percent of the child under-five mortality (You et al., 2015). Preterm birth is the leading cause of child mortality in almost all countries worldwide including Kenya as well as a major determinant of child morbidity (WHO, 2015b). Preterm birth as defined by the World Health Organization (WHO) include all births occurring before 37 completed weeks of gestation or less than 259 days from the first day of a woman's last menstrual cycle (Blencowe et al., 2013).

Preterm birth has been reported to be the major cause of death and significantly contributes to loss of human potential among the survivors all over the world. Complications related to preterm birth are the most contributor of death among the neonates. Out of 3.1 million neonatal mortality that occurs in the world per year, 35 percent are as a result of complications that are directly related to preterm birth (Blencowe et al., 2013). Preterm birth also carry greater disease burden due to long-term adverse consequences for health as children who are born preterm have higher incidence of respiratory diseases, sensory deficit, cerebral palsy, impaired learning ability in comparison to those born at term (WHO, 2017). An estimated 15 million babies worldwide are born too early each year with the rate increasingly being reported in almost all countries with available and reliable data. In every 10 babies born worldwide, more than one is a preterm birth with more than a million of them dying from complications directly related of preterm birth (WHO, 2017). Sub-Saharan Africa and South Asia is where most of these preterm births and deaths occurs in the world as they accounts for more than 60 percent of the preterm births and over 80 percent of deaths directly related to preterm births complications. This can be attributed to the fact that almost half of these births do take place at home under the supervision of unskilled midwife (WHO, 2017).

Kenya is among the top 15 countries with the highest rate of preterm birth worldwide according to the WHO with a prevalence rate of $12 \%$. Kenya has also been ranked number $13^{\text {th }}$ with the highest burden of neonatal deaths from complications related to preterm birth worldwide (Blencowe et al., 2013). 193,000 babies are born preterm each year and 13,000 children underfive die from complications directly related to preterm birth in Kenya (USAID, 2015). Factors or events that lead to preterm births are still not adequately understood since preterm birth is a complex syndrome and the causes or factors are thought to be multiple. It is not clear whether 
preterm birth do come about through the interaction of several pathways or the independent effect of each pathway (Barros et al., 2015; Hidayat et al., 2016). Preterm birth has been linked to medical conditions of the mother or fetus such as infections, diabetes and hypertensions, multiple gestations and even genetics (WHO, 2017). In order to enhance clear understanding of preterm birth and improved targeted interventions, Barros et al., (2015) came up with clinical phenotype classification based on severe maternal, fetal and placental conditions causally associated with preterm births. This includes conditions the mother and fetus presents with before delivery, placental pathologies, indications of parturition and pathway to delivery. Hence, this study aims to analyze the clinical phenotypes based on maternal, fetal and placental conditions associated with preterm birth in JOOTRH. The result will be of great importance in predicting the occurrence of preterm birth in order to reduce the incidence of preterm birth. This will help to improve the neonatal outcome and facilitate the reduction of neonatal mortality which will go a long way in reducing child mortality.

\section{PROBLEM STATEMENT}

The problem of preterm birth and its related death is a global health problem, affecting families everywhere in the world with the vast majority occurring in middle- and low-income countries including Kenya. Preterm babies born in these countries face high morbidity and mortality rates from infections and respiratory distress as half of them dies due to lack of feasible, cost-effective care such as warmth, breastfeeding support and basic care for infections and breathing difficulties compared to high-income countries where almost all these babies survives. In 2015, the under-five mortality rate in low-income countries was 76 deaths per 1000 live births which translate to about 11 times the average rate in high-income countries ( 7 deaths per 1000 live births) (WHO, 2015a). On the other hand, those who survived infancy have higher incidences of learning difficulties, recurrent respiratory illnesses and psychomotor problems since their growth and developmental milestones are adversely affected extending to later life which results into physical, social, psychological and educational problems. They also require prolonged hospital stays after birth, frequent hospital admissions with increased risks of chronic illnesses putting their parents in deep social and financial crisis (Wagura, 2014).

In spite of the improvement in the child survival in Kenya in 2015 as demonstrated with a substantial decline in the child under-five mortality rate between 1990 and 2014 from 90 deaths per 1000 live births to 52 deaths per 1000 live births (KNBS, 2014) and improved neonatal care resulting to reduction in neonatal mortality rate from 33 deaths per 1000 live births in 1990 to 22 deaths per 1000 live births in 2014 (KNBS, 2015; KNBS, 2014; MOH, 2016); preterm birth remains the leading determinants of neonatal mortality and morbidity associated with lifelong disabilities as it contributes to $35 \%$ of all neonatal mortality in the country and has been identified to be the leading cause of deaths among the neonates compromising the attainment of the Sustainable Development Goal (SDG) 3.2 target to end Newborn and Child preventable deaths by 2030 (Ministry of Health, 2016). According to the Kenya demographic and health survey 2014 (KNBS, 2014), the six counties (Kisumu, Siaya, Homabay, Migori, Kisii and Nyamira) curved from the former Nyanza province as per the new constitution has got the highest child under-five mortality rate in the country at 82 deaths per 1000 live births against the national 52 deaths per 1000 live births (KNBS, 2015). Infant mortality rate in Kisumu County is still high at 95 deaths per 1000 live birth which is above the national average of 39 deaths per 1000 live birth and the child under-five mortality rate of 133 deaths per 1000 live births (County, 2013; KNBS, 2014). JOOTRH in Kisumu County reports more than 600 live births per month 
against a monthly target of 500 live births which includes more than 60 preterm live births according to the hospital Maternity Register $\mathrm{MOH}$ 333. There exist very few intervention strategies for prevention of preterm birth at the disposal of policy makers, clinicians and managers of various programs related to preterm birth. This can partly be attributed to the fact that not much of the knowledge on the causes and mechanism of preterm birth is available. In the absence of this knowledge, the occurrence of preterm birth together with its consequences will continue. On the other hand, preterm birth has not been prioritized as a health problem in the absence of standardized collection of data showing the burden of preterm birth and its related mortality and morbidity nationally; has not been captured in the Kenya Demographic and Health Surveys.

\section{OBJECTIVES}

The main objective of this study is to investigate the clinical phenotypes (maternal, fetal and placental conditions) associated with preterm birth in JOOTRH.

i. To determine the maternal conditions associated with preterm births in JOOTRH.

ii. To establish the fetal conditions associated with preterm births in JOOTRH.

iii. To determine the placental conditions associated with preterm births in JOOTRH.

\section{CONCEPTUAL FRAMEWORK}

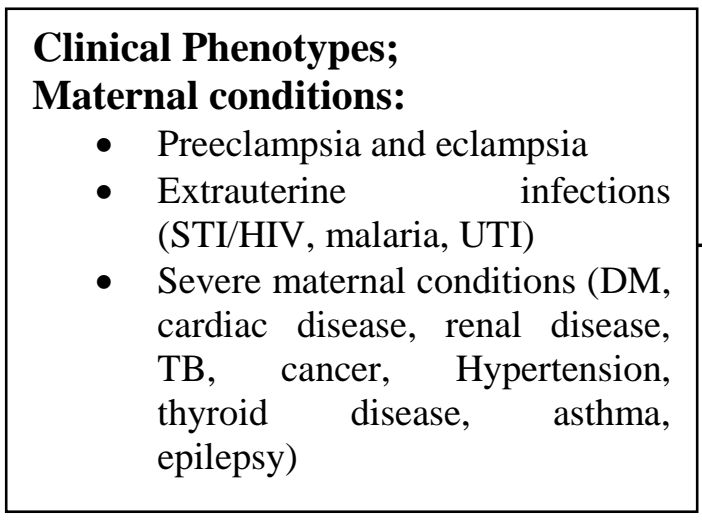

\section{Fetal conditions:}

- Multiple fetuses

- Fetal anomaly

- IUGR

- Antepartum stillbirth

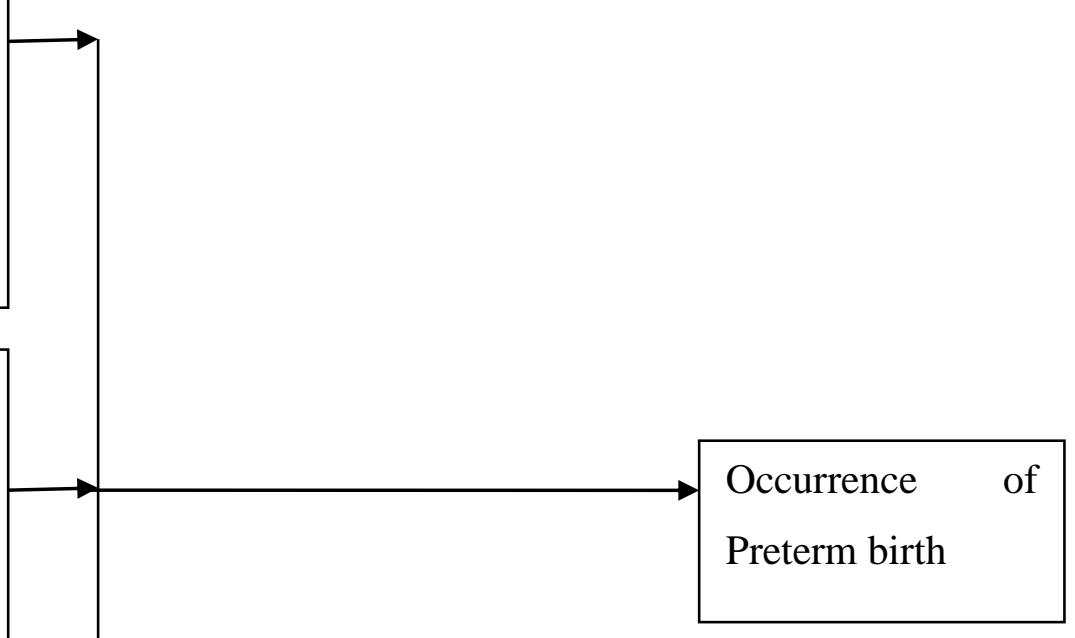

\section{Placental conditions: \\ - APH/ early pregnancy bleeding (Placenta previa and placenta abruption)}

\section{1: Conceptual Framework Adopted from Literature Review}


Figure 1 illustrates the conceptual framework. The researcher examined the occurrence of preterm birth as a result of maternal, fetal and placental conditions due to their direct effect on the initiation of labour or initiated by the care giver due to clinical severity of the conditions. Maternal, fetal and placental conditions were conceptualized based on Barros' phenotypic classification system. The maternal conditions were clustered into preeclampsia and eclampsia, extrauterine infections to include HIV, malaria and UTI and Severe maternal conditions which include diabetes, hypertension prior to pregnancy, cardiac disease, asthma, renal disease, TB, cancer, thyroid disease and epilepsy. Fetal conditions were clustered into multiple fetuses, fetal anomaly, intrauterine growth retardation (IUGR) and antepartum stillbirth. Placental conditions clustered into Antepartum hemorrhage/ early pregnancy bleeding (placenta previa and placenta abruption). These clinical phenotypes are reviewed in detail in the literature review.

\section{LITERATURE REVIEW}

Globally, despite remarkable progressed that was made in the improvement of child survival between 1990 to 2015, the millennium development goal (MDG) 4 target of reducing under-five mortality rate by two-third was not achieved (Liu et al., 2016); even though the child under-five mortality rate did show some decline between 1990 and 2015 by 53 percent from an estimated rate of 91 deaths per 1000 live births to 43 deaths per 1000 live births (WHO, 2015a). However, Sub-Saharan Africa still remains the region in the World with the highest under-five mortality rate compared to other regions with 1 in 12 children dying before celebrating his or her $5^{\text {th }}$ birthday. This is higher compared to the average ratio of 1 in 147 children in high-income countries (You et al., 2015). Preterm birth remains a major health problem worldwide and is currently becoming a great concern. The increase of preterm birth is being reported in almost all countries worldwide with an increase in the risk for mortality and morbidity in the first year of life among children of under-five years of age (Parets et al., 2014); it is the leading cause of death among this children (WHO, 2015b). On the other hand, early neonatal deaths accounts for 75 percent of all neonatal deaths worldwide due mainly to preterm birth at 40 percent (Lloyd, 2013).

Preterm birth is the birth of an infant before 37 weeks of gestation are complete. According to WHO, subgroup of preterm births based on gestational age at delivery include extremely preterm ( $<28$ weeks), very preterm ( 28 to $<32$ weeks), moderate preterm (32 to $<34$ weeks) and late preterm (34 to 37 weeks) (WHO, 2015b).The preterm birth is further categorized according to modes of clinical presentation; Spontaneous preterm birth (SPTB) and indicated preterm birth (IPTB). The SPTB include premature onset of labour (POL) and preterm premature rupture of membrane (PPROM). Premature onset of labour (POL) is defined as present of regular rhythmic contractions that is accompanied by cervical changes with an intact membrane while Preterm premature rupture of membrane (PPROM) is defined as spontaneous rupture of membranes before 37 weeks of gestation are complete without contractions. POL accounts for $40-45 \%$ of cases of preterm births and PPROM is seen in $25-30 \%$ of preterm births. IPTB on the other hand incorporate the induction of labour or caesarian section is carried out due to maternal or fetal reasons and accounts for 25-35\% of cases of preterm birth (WHO, 2015b). Babies born before 37 completed weeks of gestation have higher risk of serious disability or death. The final weeks of pregnancy are very critical for the developing baby in the uterus of the mother as many organ systems require the final weeks of pregnancy to develop fully and function adequately. They include the brain, lungs and liver. Some serious problems or disability that the baby born before 37 completed weeks of gestation may experience include respiratory, neurological, 
ophthalmology and digestion problems as well as delayed developmental milestones (Parets et al., 2014).

Globally, it is estimated that $11.1 \%$ of all live births were born preterm in 2015 across 184 countries in the World with the rate ranging from approximately 5\% in some countries in Developed World like Northern European to $18 \%$ in some countries in Sub-Saharan Africa and South Asia (WHO, 2017). In United States, the incidence rate of preterm birth stood at $11.4 \%$ in 2013 (Centre for Disease and Control/NCHS, 2015). This is similar to another study by Rosseto et al., (2015) in Brazil between 2000 and 2013 which indicated an increase in the rate of preterm birth at an average of $0.54 \%$ per year from $7.9 \%$ in 2000 to $11.2 \%$ in 2013 . A study in USA also showed that out of the total preterm births reported, extremely preterm $(<28$ weeks gestation) accounted for $5 \%$, very preterm ( 28 to $<32$ weeks gestation) $15 \%$, moderate preterm (32 to $<34$ weeks gestation) $20 \%$ with most preterm birth (70\%) being late preterm (34 to <37 weeks gestation) (Pignotti et al., 2015). A study in Brazil revealed that among the preterm births, 64.6\% were spontaneous and $35.4 \%$ were medically indicated and only $7.4 \%$ of the preterm births occurred below 28 weeks of gestation with almost $79 \%$ occurring between 32 to 36 weeks of gestations (Passini Jr et al., 2014). This was comparable to a study conducted in India which also demonstrated that $61.68 \%$ were late preterm births among all preterm births that occurred during the period of study (Karegoudar et al., 2014). A study by Shah et al.,( 2014) in Bangladesh showed that among the babies born during the period of study, 22.3\% were born before 37 complete weeks of gestation where $12.3 \%$ were late preterm born at 35- 36 weeks of gestation, $7.1 \%$ were moderate preterm born at 32-34 weeks of gestation and $2.9 \%$ were very preterm born at 28-31 weeks of gestation. A study by Iyoke et al., (2014) in Southern East of Nigeria, showed that out of 3760 live births during the period of study, 636 were born preterm with a prevalence rate of $16.9 \%$. A study similar with the one that showed a prevalence rate $16.8 \%$ of preterm birth in Lagos, Nigeria where $4.7 \%$ were very preterm at $22-31$ weeks, $4.5 \%$ were moderate preterm at 32-34 weeks and 7.7\% were late preterm at 35-36 weeks (Butali et al., 2016). In Kenya, report released by the ministry of health indicates that out of 1.5 million live births annually, 188, 000 are born preterm which means that one out of every eight children born in the county is a preterm and this is a concern since preterm birth is the major contributor of neonatal mortality in the country (Ooko, 2014).

Preterm births are more associated with maternal, fetal and placental conditions. A study by Global Alliance to Prevent Prematurity and Stillbirth in Brazil, China, India, Italy, Kenya, Oman, United Kingdom and United State reported that seventy percent of the preterm births were associated with severity of the maternal, fetal and placental conditions due to their direct effect in initiating preterm labour resulting into preterm birth or from care giver initiated interventions including caesarian section (Barros et al., 2015). Thus the study aim to utilize the Barros et al.,(2015) clinical phenotype classification system to help enhance the understanding of the causes of preterm birth in JOOTRH since the focus on decision to create classification system was for use in both population surveillance and research so that whenever preterm births are discussed in terms of specificity or are being studied and compared across the population or overtime, there is a consistency in definition which are easily understood and acceptable. Hence, the maternal, fetal and placental conditions are conceptualized based on Barros' phenotypic classification system which is strongly associated with preterm birth. Maternal conditions include preeclampsia/eclampsia, extaruterine infections that include UTI, malaria and STIs/HIV and severe maternal conditions including hypertensions prior to pregnancy, diabetes mellitus, respiratory diseases i.e., asthma and other bronchial or pulmonary diseases, maternal anaemia, 
hormonal diseases that include adrenal disease, thyroid disease, parathyroid disease and polycystic ovaries, and gastrointestinal disease. Fetal conditions include multiple gestation, intrauterine growth retardation (IUGR), fetal anomalies and antepartum stillbirths. Placental conditions include placenta abruption, placenta previa and other bleeding after 20 weeks. According to a study by Brown et al., (2015) in Canada, a phenotype was said to be present if the mother had one or more conditions in a given phenotype (maternal, fetal and placental) according to the available clinical information in the mothers' hospital records. In the study, preterm births were seen to be affected by more than one condition or only one condition within a given phenotype or more than one phenotype.

The occurrence of preterm births have been associated with multiple maternal conditions including preeclampsia/eclampsia, maternal anaemia and malaria, UTI, HIV, essential hypertension, renal disease, DM and TB, cancer, asthma, thyroid disease, epilepsy and cardiac disease. (Barros et al., 2015) phenotypically classified these conditions into preeclampsia/eclampsia, extrauterine infections and severe maternal conditions. A study in china showed that most maternal conditions associated with preterm births contributed mostly to late preterm (Lu et al., 2015). A similar finding was also seen in a study by Brown et al., (2015) in Canada, which revealed that maternal conditions associated with preterm births with increased odds of medically indicated late preterm birth included hypertension, diabetes mellitus, respiratory diseases, aneamia, hormonal disease, gastroinstestinal disease and preeclampsia/eclampsia. This was also similar to a study done by Shapiro-Mendoza et al., (2014) in USA, which found that mothers with hypertensive disorders in pregnancy and diabetes were more likely to have late preterm births. This could be explain by the fact that most of these maternal conditions worsen during pregnancy and becomes life threatening, necessitating medical interventions where pregnancy is terminated early or most of these conditions makes it very difficult for mothers to carry pregnancy to term.

Preeclampsia is a disorder in pregnancy characterized by high blood pressure, generalized edema and proteinuria and if left unattended to, it complicate into eclampsia which is characterized with fits. The effects of these conditions to the fetus include preterm birth due to indicated preterm delivery, IUGR and antepartum stillbirths (Neiger, 2017). Studies have placed these two conditions mostly referred to as hypertensive disorders of pregnancy to be the most maternal conditions associated with poor perinatal outcomes including preterm births (Hidayat et al., 2016). In India, a study by Rao et al., (2014) to determine risk factors for preterm births showed hypertensive disorders of pregnancy to be significantly associated with preterm births as they were the commonest risk factor for preterm births (21.4\%). A similar finding was also reported by Kiondo et al., (2014), in Uganda, in determining adverse neonatal outcome among mothers with preeclampsia where it was noted to be the leading cause of adverse neonatal outcomes as those with preeclampsia were seen to be ending up having preterm births. In Africa, a study by Chiabi et al., (2013) in Cameroon in determining risk factors for preterm births from hospital records showed no association of maternal conditions such as preeclampsia, eclampsia, malaria, PPROM, prolonged rupture of membranes, olygohydromnious and diabetic mellitus with preterm births and having UTI increases the chances of mothers having preterm birth as well as the number of ANC visits. However, a study findings by Akintayo et al.,(2015) in Nigeria, showed that hypertension, preeclampsia and eclampsia were associated with preterm birth. this was also seen in Hidayat et al., (2016) findings in Indonesia, where it was found that mothers with hypertension, anaemia among other factors including maternal age of below 20 years, attended ANC less than 4 visits and history of previous preterm births were associated with 
preterm births. In Nigeria, hypertensive disorders of pregnancy were reported to increase the odds of late preterm births among the participants (Butali et al., 2016).

According to Blencowe et al., (2013) in United Kingdom, maternal infections plays an important role in preterm births. Urinary tract infections (UTIs), malaria, bacterial vaginosis, HIV and syphilis are all associated with preterm births. These infections have been noted to compromise the fetal circulation by inhibiting proper circulation across the placenta, resulting into poor oxygenation and nutrient supply to the fetus (Garcia-Basteiro et al., 2017). A study carried out in Mozambique by Garcia-Basteiro et al., (2017) clearly showed that maternal HIV infection was associated with the occurrence of preterm births. A study finding supported by Gebreslasie, (2016) , in Ethiopia, who also showed that HIV positive status of a woman was significantly associated with preterm birth as mothers who were HIV positive had increased chances of having a preterm birth. This is contrary to a study finding conducted in Malawi which found no existence of an association between HIV status of mothers and preterm birth but noted malaria and anaemia as risk factors for preterm births (van den Broek et al., 2014). This study was supported by Abdo et al., (2016) in Ethiopia, who found that mothers who had malarial infections during pregnancy were more likely to have adverse birth outcomes including preterm births compared to those who did not have malarial infections. Moreover, a hospital based study in India, showed that the common risk factor for preterm birth was UTI at 34\%, among other factors which included PPROM (22\%), abortion (16\%) and past obstetric history of preterm birth (8\%) that were seen to be related to preterm birth (Garg et al., 2017). The same was also reported by Passini Jr et al., (2014) in Brazil, where UTI was the most risk factor for preterm births. A study by Temu et al., (2016) in Tanzania, to determine the maternal and obstetric factors associated with preterm birth reported preeclampsia and UTI in pregnancy as maternal conditions together with other factors such as living alone, having no formal education, being a peasant or business woman, history of miscarriage, inadequate ANC visits to be associated with having a preterm delivery among the participants. A finding supported with another study in Tanzania, which showed that having preeclapsia/ eclampsia, chronic hypertension, maternal anaemia, HIV status as well as undergoing caesarian section delivery increases the chances of having a preterm birth (Mitao et al., 2016). Similar finding was also seen by Mahapula et al., (2016) in Tanzania, in determining risk factors for preterm birth in Dar es Saalam reported that untreated UTI in pregnancy and inadequate ANC visits were found to be significant risk factors for preterm births. A study in Nigeria by Butali et al., (2016), to examine the characteristics and risk factors for preterm births reported that mothers who were HIV positive and were on ARVs care had late preterm births. This was attributed to the care which was seen to prevent them from having early or moderate preterm births. In Kenya, a study carried out in one referral hospital revealed that mothers who had UTI in pregnancy were more likely to have late preterm births (Wagura, 2014).

Abdo et al., (2016), in Ethiopia, in assessing the prevalence and associated factors of adverse birth outcomes among deliveries revealed that the study participants who presented with malarial infection, anaemia in pregnancy, being less than 20 years, did not attend ANC clinic, was employed as well as dwells in rural areas were more fond of having adverse birth outcome including preterm birth. Similar finding was also reported in a study carried out in the Republic of Korea to assess the risk of amaemia before pregnancy which revealed that maternal anaemia before pregnancy was significantly associated with the occurrence of preterm birth. It was also noted in the same study that maternal anaemia and IUGR were related (Yi et al., 2013). Another study by Ntiloudi et al., (2017) in Greece, to assess pregnancy outcome in women with 
congenital heart disease showed that mothers with cardiac disease often complicate during pregnancy resulting in preterm birth. A study in USA to evaluate the outcomes of preterm births, low birth weight and small for gestational age of HIV exposed infants revealed that TB is related to PTB with effect increasing if HIV coexist together with TB (Slyker et al., 2014). Delnord et al., (2017) in France, in investigating whether risk factors for preterm and early-term are similar revealed that maternal conditions associated with preterm births were anaemia and gastrointestinal disease which resulted into late preterm birth. On the other hand, a study finding by van den Broek et al., (2014) in Malawi, revealed that persistent maternal malaria was associated with late preterm birth and maternal anaemia was seen to double the odds of early preterm birth.

A study by Rosseto et al., (2015) in Brazil, in determining the growing trends of moderate preterm births showed that multiple gestations, IUGR and fetal congenital malformations were significantly associated with preterm births $(\mathrm{p}<0.001)$. According to Brown et al., (2015) in Canada, intrauterine growth retardation, fetal anomaly and polyhydromnios were increasingly associated with preterm births. Multiple fetuses are associated with preterm birth due to over distension of the uterus particularly higher order multiple gestation, increased intrauterine volume and cervical incompetence. Multiple gestations accounts for merely 2 to $3 \%$ of all births and $10 \%$ of all preterm births (Field et al., 2016). According to a report from a finding in the United State in 2013, 9.7\% of singleton birth were preterm compared with $56.6 \%$ of twin births and $93.3 \%$ of triplet births which could be attributed to increased use of medically assisted reproductive technique in the treatment of infertility (CDC/NCHS, 2015). A study by Akintayo et al., (2015) in Nigeria revealed that multiple pregnancy was associated with preterm births. This finding was supported by the result of another study in Cameroon, which showed multiple gestation and presence of fetal malformation to significantly influenced the occurrence of preterm births among the study participants (Chiabi et al., 2013). Moreover, another study in Tanzania, to determine maternal and obstetric factors associated with preterm birth showed that multiple gestation was associated with preterm births (Temu et al., 2016). A similar finding was also reported by Mahapula et al., (2016) in Tanzania, where multiple gestation was among the risk factors significantly associated with the occurrence of preterm births among the study participants. Multiple preterm births are more likely to occur in late preterm period as a result of spontaneous preterm labour due to distended uterus and increased intrauterine volume (Field et al., 2016). In Kenya, in a study to determine prevalence of preterm birth revealed that mothers with multiple gestation had increased risk of delivering late preterm births (Wagura, 2014).

The existence of a major congenital abnormality intrauterine increases the risk of having a preterm birth. A study carried out by Passini Jr et al., (2014) in Brazil, in determining factors and prevalence associated with spontaneous preterm births showed that fetal malformation and polyhydramnios to be significantly associated with preterm births and both are thought to be interrelated. Polyhydramnios is thought to lead to over-distension of the uterus resulting into uterine contractility which eventually leads to preterm delivery. In UK, a study by Field et al., (2016) to determine late and moderate preterm births showed that fetal anomalies were more common with late preterm births. In Ethiopia, a study finding showed that out of 28 preterm births, 6 had fetal anomaly (Abdo et al., 2016). Intrauterine growth restriction (IUGR) is where a fetus is weighing less than 10th percentile for gestational age; the developing baby weighs less $90 \%$ of other babies of the same gestational age as a result of maternal conditions, fetal anomalies or infections and placental conditions. IUGR has been associated with an increased incidence of preterm birth which is thought to be as a result of a hostile intrauterine environment 
to the growing fetus (Slyker et al., 2014). Study findings in Tanzania, revealed that low birth weight of the fetus was increasingly related with preterm births where IUGR was also seen to occur in late preterm births (Temu et al., 2016; Mitao et al., 2016). Antepartum stillbirth which is death occurring before the initiation of labour from 20 weeks of gestation has been associated with preterm births. According to Hirst et al., (2016), in a study findings by Global Alliance to Prevent Prematurity and Stillbirth (GAPPS), revealed that preeclampsia, hypertension prior to pregnancy, HIV/AIDS, multiple gestation, IUGR and APH in addition to low socio-economic status, being single, advance maternal age were associated with antepartum stillbirth which increasingly results into preterm births where it accounted for a greater proportion of extremely preterm births at $72 \%$ compared to late preterm at $38 \%$. A finding supported by a study in Australia, which showed that having diabetics mellitus and hypertension prior to pregnancy were associated with increased risk for stillbirth with mixed results for preeclampsia and eclampsia which were both found to raise the risk for antepartum stillbirth (Ibiebele et al., 2017). Ibrahimou et al., (2015), in a study in USA, showed that antepartum stillbirth was associated with various conditions that included eclampsia, hypertension, diabetes, multiple gestations and placenta abruptions that often result into premature termination of pregnancy.

Placental conditions comprise of placenta previa and placenta abruption that are the major causes of antepartum hemorrhage (APH) or early pregnancy bleeding. Placenta abruption is defined as the sudden separation of a significant portion of the placenta from its underlying maternal blood supply prior to delivery and is one of the major contributing factors to the hypoxic status of the fetus intrauterine. It is associated with a number of adverse birth outcomes including preterm births, intrauterine growth restriction (IUGR) and antepartum stillbirth (Ozer, 2013). Placenta previa occurs when a placenta partially or totally covers the mother's cervix which can cause severe bleeding during pregnancy and delivery. Antepartum hemorrhage (APH) or early pregnancy bleeding has been associated with preterm births. APH/early pregnancy bleeding resulting from Placenta previa and Placenta abruption which are low laying placenta intrauterine and premature separation of a normally situated placenta in the uterus respectively are highly associated with preterm birth (Ananya et al., 2015). A finding supported by a study in Tanzania which revealed that placenta abruption and placenta previa which are often life threatening to both the mother and the fetus always results in termination of pregnancy to save both lives (Mitao et al., 2016).

A study by Passini Jr et al., (2014) in Brazil, revealed that vaginal bleeding during pregnancy to be strongly associated with preterm births. This finding was supported by Hidayat et al., (2016), in a study conducted in Indonesia, to determine factors associated with preterm birth which revealed that mothers with antepartum hemorrhage (APH) which include placenta previa and abruption, were seven times more likely to deliver preterm births in comparison to their counterpart with no APH. Preterm birth was found to be high among women with placenta previa compared to mothers with normal placentation whereby most of the women $55 \%$ had preterm birth. However, a finding by Rao et al., (2014) in India, in a study to determine risk factors for preterm deliveries showed that there was no significant association between APH and preterm birth. A study by Hidayat et al., (2016) also demonstrated that women with placenta previa were advance in maternal age with multiple deliveries compared to those with normal placenta implantation which means that the higher the maternal age and high parity the higher the chances of placenta previa and most likely of having a preterm birth. According to a study in Turkey to determine early preterm delivery due to placenta previa showed that most preterm births associated with placenta previa occurs in the late preterm births (Ozer, 2013). A similar 
finding by Lu et al., (2015) in China, to determine risk factors associated with late preterm births showed placenta abruption and previa to be associated with late preterm births. A study by Garg et al., (2017) in Ethiopia, to assess the outcome of preterm births showed that placenta abruption was associated with preterm births and it occurred more with late preterm births as a result of caesarian section to end the pregnancy. However, a study by Wagura, (2014), in Kenya showed APH to be associated with early preterm birth. The sudden separation of a normally situated placenta from its underlying maternal blood supply has been associated with hypertensive disorders of pregnancy and other maternal conditions.

\section{MATERIALS AND METHODS}

This was a hospital based cross-sectional study design that utilized both descriptive and inferential statistics. The designed allowed for data to be collected once and was used in determining the clinical phenotypes associated with preterm birth. Both quantitative and qualitative techniques were used in data collection, analysis and presentation. The independent variable in this study was clinical phenotypes based on maternal, fetal and placental conditions which included preeclampsia/eclampsia, extrauterine infections (HIV, malaria and UTI) severe maternal conditions (diabetics, renal disease, TB, asthma, anaemia, cardiac disease, epilepsy), multiple pregnancies, IUGR, fetal anomaly and antepartum stillbirth. APH/early bleeding that included placenta previa and placenta abruption. They were measured through the categorical response of either the presence or absence of the conditions. Dependent variable in this study was the occurrence of preterm birth. Based on gestational age; preterm birth was categorized as extremely preterm ( $<28$ weeks), very preterm ( 28 to $<32$ weeks), moderate preterm (32 to $<34$ weeks) and late preterm (34 to <37 weeks).

The study was conducted at the Maternity department of Jaramogi Oginga Odinga Teaching and Referral Hospital (JOOTRH) in Kisumu County. It is the major teaching and referral hospital that serve almost all counties in former Nyanza, Western province and North Rift of Kenya. The hospital is serving a population in excess of 5 million with an average annual outpatient visits at 197,200 and in-patient admission of about 21,000. The study took place in the maternity department. The Maternity department comprises of labour ward, newborn unit and postnatal ward. Labor ward has a capacity of 17 beds with 5 delivery couches. The postnatal ward has a bed capacity of 60 beds while the newborn unit has a capacity of 15 beds and 21 baby cots as well as 16 incubators. Antenatal ward is a small section of the postnatal ward and has a bed capacity of twenty beds. Labor ward has four spacious rooms. Two of the rooms are delivery rooms which are further subdivided into two sections each having two delivery couches. For the other two rooms, one serves as an observation room for women after delivery and the other as first stage for those in active phase of labor. On average 600 deliveries are conducted per month including caesarian section with preterm births of more than 55 neonates per month according to the hospital records (Maternity register, $\mathrm{MOH}$ 333). The study population comprised of all women who presented to the maternity of the JOOTRH and delivered a preterm baby alive or stillborn during the period of study. Their gestations were confirmed by dates from the first day of the last menstrual cycle (LMP) which appeared on their Maternal and Child booklet, patients' records and gestational wheel was used to get their EDD. Ultrasonography was used only where it was necessary. Also post gestational age assessment of the preterm baby was done by use of new Ballard score (technique of gestational age assessment of the fetus to assess the gestational maturity of the newborn) between the month of July 2017 to January 2018. 
Purposive sampling method was used in this study to select all potential study participants, who met the inclusion criteria of having had a preterm birth alive or stillbirth. This sampling method was used because it enabled the researcher to capture all eligible study participants who met the inclusion criteria and were readily available. The research team was informed that on average 60 preterm babies are born in the department per month. Recruitment was done on a daily basis by the research team. Any mother who had a preterm birth alive or stillbirth was selected as confirmed by the mothers' gestation of below 37 weeks from the first day of the last menstrual cycle. This was confirmed by checking at her MCH booklet or in-patient records in case she could not recall the dates. Ultrasound report was also used in cases where the mother was not sure of her EDD as requested. The score assigned sum up to the gestational age of the newborn based on the physical and neuromuscular criteria which allows for the estimation of the gestational age that ranges between 20 weeks to 44 weeks. Mother who met the inclusion criteria and gave her informed consent or assented was then recruited to participate in the study. All questionnaires were reviewed for completeness before data entry was commenced. Data was then cleaned and sorted to eliminate any information that was inaccurate, inconsistent as well as omissions omitted. Data was then coded and entered into a computer into respective categories and analysis was done by SPSS (Statistical Package for Social Science) version 23.0. Descriptive statistic which comprised of frequency distribution and percentage were used to summarize data. Inferential statistics to include Pearson Chi squire test and Fisher's Exact Test was performed to assess the significance of association between the preterm births and the categorical variables. Fisher's exact test was used when table cells had expected values or frequencies less than five (5). Bivariate analysis was used to assess the strength of association between preterm birth and the categorical variables and correct any confounder. A p value of $<0.05$ was used as the criteria for the statistical significance. Results were presented using frequency tables and narrative description.

\section{STUDY RESULTS}

The study assessed the association between social demographic characteristics of the participants and preterm births. Using Fisher's Exact test, maternal age was significantly associated with preterm births $(\mathrm{p}<0.05)$. However, using Fisher's Exact test, the results showed no significant association between participant's marital status and preterm births $(\mathrm{p}=0.034)$. Moreover, the educational level, employment status and residence of the study participants had no significance association with preterm births $(\mathrm{p}>0.05)$ on Pearson Chi square test as shown in table 1.

Table 1: Association between social demographic characteristics and preterm births

\begin{tabular}{lcccccc}
\hline & \multicolumn{7}{c}{ Preterm births gestational ages } & & \\
Characteristics & weeks & $\begin{array}{c}\mathbf{2 8} \text { to }<\mathbf{3 2} \\
\text { weeks }\end{array}$ & $\begin{array}{c}\mathbf{3 2} \text { to }<\mathbf{3 4} \\
\text { weeks }\end{array}$ & $\begin{array}{c}\mathbf{3 4} \text { to }<\mathbf{3 7} \\
\text { weeks }\end{array}$ & $\begin{array}{c}\text { Total } \\
\text { n=178 }\end{array}$ & $\begin{array}{c}\text { Significance } \\
\text { level }\end{array}$ \\
\hline $\begin{array}{l}\text { Age } \\
\quad \text { 18yrs }\end{array}$ & 6 & 5 & 4 & 1 & 16 & Fishers Exact \\
18yrs to 24yrs & 10 & 28 & 25 & 33 & 96 & \\
25yrs to 31yrs & 4 & 5 & 13 & 20 & 42 & P value=0.016 \\
32yrs to 38yrs & 3 & 0 & 5 & 10 & 18 & \\
39yrs and above & 0 & 1 & 2 & 3 & 6 & \\
\hline Educational level & & & & & & \\
Informal & 5 & 7 & 6 & 5 & 23 & $\chi^{2}=11.304$ \\
Primary level & 7 & 14 & 15 & 14 & 50 & $\mathrm{df}=9$ \\
\hline
\end{tabular}


International Journal of Current Aspects, Volume 3, Issue III, 2019, PP 154-174, ISSN 2616-6976

iJCAB

\begin{tabular}{lcccccc} 
Secondary level & 6 & 12 & 21 & 36 & 75 & $\mathrm{P}$ value $=0.255$ \\
Tertiary level & 5 & 6 & 7 & 12 & 30 & \\
\hline Marital status & 10 & 12 & 14 & 14 & 50 & Fishers Exact \\
Single & 12 & 27 & 34 & 50 & 123 & \\
Married & 0 & 0 & 1 & 2 & 3 & $\mathrm{P}$ value $=0.340$ \\
Widowed & 1 & 0 & 0 & 1 & 2 & \\
Separated/divorced & 5 & 6 & 8 & 15 & 34 & $\chi^{2}=3.721$ \\
Employment status & 5 & 7 & 13 & 18 & 43 & $\mathrm{df}=6$ \\
Self employed & 13 & 26 & 28 & 34 & 104 & $\mathrm{P}$ value $=0.714$ \\
Employed & 11 & 15 & 18 & 31 & 75 & $\chi^{2}=1.577$ \\
Unemployed & & & & & & $\mathrm{d}=3$ \\
Residence & 12 & 24 & 31 & 36 & 103 & $\mathrm{p}$ value $=0.665$ \\
Rural & & & & & & \\
\end{tabular}

The study also examined the association between selected obstetric characteristics of the study participants and preterm births; history of abortion/miscarriage, history of previous preterm births and number of antenatal clinic (ANC) attendance during the current pregnancy. Using Fisher's Exact test, history of abortion or miscarriage, previous preterm birth and number of ANC attendance had no significance association with preterm births $(p>0.05)$ as shown in table 2.

Table 2: Association between selected obstetric characteristics of participants and preterm births

\begin{tabular}{|c|c|c|c|c|c|c|}
\hline \multicolumn{7}{|c|}{ Preterm births gestational ages } \\
\hline Characteristics & $\begin{array}{c}<28 \\
\text { weeks }\end{array}$ & $\begin{array}{c}28 \text { to }<32 \\
\text { weeks }\end{array}$ & $\begin{array}{c}32 \text { to }<34 \\
\text { weeks }\end{array}$ & $\begin{array}{c}34 \text { to }<37 \\
\text { weeks }\end{array}$ & $\begin{array}{c}\text { Total } \\
\mathbf{n}=\mathbf{1 7 8}\end{array}$ & $\begin{array}{c}\text { Significance } \\
\text { level }\end{array}$ \\
\hline \multicolumn{7}{|l|}{$\begin{array}{l}\text { History of } \\
\text { Abortion/miscarriage }\end{array}$} \\
\hline Yes & 4 & 4 & 9 & 13 & 30 & Fishers Exact \\
\hline No & 19 & 35 & 40 & 54 & 148 & $\mathrm{P}=0.652$ \\
\hline \multicolumn{7}{|l|}{$\begin{array}{l}\text { Delivered preterm baby } \\
\text { before }\end{array}$} \\
\hline Yes & 3 & 1 & 4 & 5 & 13 & Fishers Exact \\
\hline No & 20 & 38 & 45 & 62 & 165 & $\mathrm{P}=0.462$ \\
\hline \multicolumn{7}{|l|}{ Number of ANC visits } \\
\hline$<4$ visits & 14 & 29 & 36 & 60 & 139 & Fishers Exact \\
\hline 4 or more visits & 1 & 1 & 1 & 2 & 5 & $\mathrm{P}=0.834$ \\
\hline
\end{tabular}

Table 3 shows the maternal conditions identified among the participants. Participants who presented with preeclampsia/eclampsia on or during admission were $21.9 \%$. Those who had extrauterine infections (malaria, HIV and UTI) were $31.5 \%$ with almost half of them $(44.6 \%)$ presenting with malarial infections while those who had HIV and UTI were $30.4 \%$ and $25 \%$ 
respectively. Participants who presented with severe maternal conditions (diabetes mellitus, anemia, cardiac disease, hypertension prior to pregnancy and tuberculosis) were 53\% with majority of them (77\%) presenting with maternal anemia while those who presented with diabetes mellitus, hypertension in pregnancy, tuberculosis and cardiac disease accounted for $13.2 \%, 3.8 \%, 3.8 \%$ and $1.9 \%$ respectively.

Table 4: Maternal phenotypes of preterm births among participants

\begin{tabular}{llll}
\hline Maternal conditions & & Frequency & Proportions (\%) \\
\hline Preeclampsia/Eclampsia & Yes & 39 & 21.9 \\
& No & 139 & 78.1 \\
& Total & $\mathbf{1 7 8}$ & $\mathbf{1 0 0}$ \\
\hline Extrauterine infections & Yes & 56 & 31.5 \\
& No & 122 & 68.5 \\
& Total & $\mathbf{1 7 8}$ & $\mathbf{1 0 0}$ \\
\hline Infections & Malaria & 25 & 44.6 \\
& HIV & 17 & 30.4 \\
& UTI & 14 & 25 \\
& Total & $\mathbf{5 6}$ & $\mathbf{1 0 0}$ \\
\hline \multirow{2}{*}{ Severe maternal conditions } & Yes & 53 & 29.8 \\
& No & 125 & 70.2 \\
& Total & $\mathbf{1 7 8}$ & $\mathbf{1 0 0}$ \\
\hline Conditions & Diabetes mellitus & 7 & 13.2 \\
& Anemia & 41 & 77.3 \\
& Cardiac disease & 1 & 1.9 \\
& Hypertension prior to pregnancy & 2 & 3.8 \\
& Tuberculosis & 2 & 3.8 \\
& Total & $\mathbf{5 3}$ & $\mathbf{1 0 0}$ \\
& & &
\end{tabular}

Table 5 shows fetal conditions identified among the participants whereby those who had multiple gestations were $12.4 \%$ and those who gave birth to a fetus with anomaly accounting for $4.5 \%$. Participants who had neonates with intrauterine growth restriction (IUGR) were $21.3 \%$ with those who had an antepartum stillbirths accounting for $21.9 \%$.

Table 5: Fetal phenotypes of preterm births among participants

\begin{tabular}{llll}
\hline Fetal conditions & & Frequency & Proportion $(\boldsymbol{\%})$ \\
\hline Multiple gestation & Yes & 22 & 12.4 \\
& No & 156 & 87.6 \\
& Total & $\mathbf{1 7 8}$ & $\mathbf{1 0 0}$ \\
\hline Fetal anomaly & Yes & 8 & 4.5 \\
& No & 170 & 95.5 \\
& Total & $\mathbf{1 7 8}$ & $\mathbf{1 0 0}$ \\
\hline IUGR & Yes & 38 & 21.3 \\
& No & 140 & 78.7 \\
& Total & $\mathbf{1 7 8}$ & $\mathbf{1 0 0}$ \\
\hline Antepartum stillbirth & Yes & 39 & 21.9
\end{tabular}


International Journal of Current Aspects, Volume 3, Issue III, 2019, PP 154-174, ISSN 2616-6976

iJCAB

\begin{tabular}{lll} 
No & 139 & 78.1 \\
Total & $\mathbf{1 7 8}$ & $\mathbf{1 0 0}$ \\
\hline
\end{tabular}

Table 6 shows placental conditions identified among the participants. Slightly over a quarter of the participants $(33.4 \%)$ presented with antepartum hemorrhage (APH) or early pregnancy bleeding which includes placenta previa and placenta abruption. Most of them (73.3\%) presented with placenta abruption with those presenting with placenta previa accounting for $26.7 \%$.

Table 6: Placental phenotypes of preterm births among participants

\begin{tabular}{llll}
\hline Placental conditions & & Frequency & Proportion (\%) \\
\hline APH/Early pregnancy bleeding & Yes & 60 & 33.7 \\
& No & 118 & 66.3 \\
& Total & $\mathbf{1 7 8}$ & $\mathbf{1 0 0}$ \\
\hline APH & Placenta previa & 16 & 26.7 \\
& Placenta abruption & 44 & 73.3 \\
& Total & $\mathbf{6 0}$ & $\mathbf{1 0 0}$ \\
\hline
\end{tabular}

The study determined the association between the maternal conditions and preterm births using Fisher's Exact test. The results showed that preeclampsia/eclampsia, extrauterine infections and severe maternal conditions were significantly associated with preterm births $(\mathrm{p}<0.05)$ as shown in table 7.

Table 7: Maternal conditions associated with preterm births

\begin{tabular}{|c|c|c|c|c|c|c|c|}
\hline \multirow[b]{2}{*}{ Clinical phenotypes } & & \multicolumn{6}{|c|}{ Gestation age of baby } \\
\hline & & $\begin{array}{l}<28 \\
\text { weeks }\end{array}$ & $\begin{array}{l}28 \text { to }<32 \\
\text { weeks }\end{array}$ & $\begin{array}{l}32 \text { to }<34 \\
\text { weeks }\end{array}$ & $\begin{array}{l}34 \text { to }<37 \\
\text { weeks }\end{array}$ & Totals & Significance \\
\hline \multirow[t]{2}{*}{ Preeclampsia/Eclampsia } & Yes & 2 & 4 & 17 & 16 & 39 & Fishers Exact \\
\hline & No & 21 & 35 & 32 & 51 & 139 & $p$ value $=0.016$ \\
\hline \multirow[t]{2}{*}{ Extrauterine infections } & Yes & 4 & 7 & 17 & 28 & 56 & Fishers Exact \\
\hline & No & 19 & 32 & 32 & 39 & 122 & $p$ value $=\mathbf{0 . 0 3 0}$ \\
\hline \multirow[t]{2}{*}{$\begin{array}{l}\text { Severe } \\
\text { conditions }\end{array}$} & Yes & 3 & 8 & 10 & 32 & 53 & Fishers Exact \\
\hline & No & 20 & 31 & 39 & 35 & 125 & $p$ value $=0.001$ \\
\hline
\end{tabular}

The study showed significant statistical association between the following fetal conditions and preterm births through the use of Fisher's Exact test; multiple gestations $(p=0.013)$, fetal anomaly $(\mathrm{p}=0.048)$ and intrauterine growth restriction (IUGR) $(\mathrm{p}=0.049)$. Using Pearson's Chi Squire Test, there was a significant association between antepartum stillbirths and preterm births $\left(\chi^{2}=8.005 ; \mathrm{df}=3 ; \mathrm{P}=0.046\right)$ as shown in table 8 .

Table 8: Fetal conditions associated with preterm births

\begin{tabular}{|c|c|c|c|c|c|c|c|}
\hline \multirow[b]{2}{*}{$\begin{array}{l}\text { Clinical } \\
\text { phenotypes }\end{array}$} & & \multicolumn{6}{|c|}{ Gestation age of baby } \\
\hline & & $\begin{array}{l}<28 \\
\text { weeks }\end{array}$ & $\begin{array}{l}28 \text { to }<32 \\
\text { week }\end{array}$ & $\begin{array}{l}32 \text { to }<34 \\
\text { weeks }\end{array}$ & $\begin{array}{l}34 \text { to }<37 \\
\text { weeks }\end{array}$ & Total & Significance \\
\hline Multiple gestation & Yes & 1 & 11 & 3 & 7 & 22 & Fishers Exact \\
\hline
\end{tabular}


International Journal of Current Aspects, Volume 3, Issue III, 2019, PP 154-174, ISSN 2616-6976

[IJCAB

\begin{tabular}{llllllll} 
& No & 22 & 28 & 46 & 60 & 156 & p value $=\mathbf{0 . 0 1 3}$ \\
\hline Fetal anomaly & Yes & 0 & 0 & 1 & 7 & 8 & Fishers Exact \\
& No & 23 & 39 & 48 & 60 & 170 & p value $=\mathbf{0 . 0 4 8}$ \\
\hline IUGR & Yes & 3 & 6 & 7 & 22 & 38 & Fishers Exact \\
& No & 20 & 33 & 42 & 45 & 140 & p value $=\mathbf{0 . 0 4 9}$ \\
\hline Antepartum stillbirth & Yes & 8 & 13 & 8 & 10 & 39 & $\begin{array}{l}\chi^{2}=8.005 \\
\mathrm{df}=3\end{array}$ \\
& No & 15 & 26 & 41 & 57 & 139 & $\mathbf{p}$ value $=\mathbf{0 . 0 4 6}$ \\
\hline
\end{tabular}

The study examined the association between the placental conditions and preterm births using Fisher's Exact test. The result showed that APH/ early pregnancy bleeding was significantly associated with preterm births at a p value of 0.025 as shown in table 9 .

Table 9: Placental conditions associated with preterm births

\begin{tabular}{|c|c|c|c|c|c|c|c|}
\hline \multirow[b]{2}{*}{ Clinical phenotype } & & \multicolumn{4}{|c|}{ Gestation age of baby } & \multirow[b]{2}{*}{ Total } & \multirow[b]{2}{*}{ Significance } \\
\hline & & $\begin{array}{l}<28 \\
\text { weeks } \\
\end{array}$ & $\begin{array}{l}28 \text { to }<32 \\
\text { weeks }\end{array}$ & $\begin{array}{l}32 \text { to }<34 \\
\text { weeks }\end{array}$ & $\begin{array}{l}34 \text { to }<37 \\
\text { weeks }\end{array}$ & & \\
\hline \multirow[t]{2}{*}{$\begin{array}{l}\text { APH/early } \\
\text { pregnancy bleeding }\end{array}$} & Yes & 4 & 18 & 21 & 17 & 60 & Fishers Exact \\
\hline & No & 19 & 21 & 28 & 50 & 118 & $p$ value $=0.025$ \\
\hline
\end{tabular}

The study finding on Bivariate analysis showed that there was a negative correlation but statistically significant relationship between preeclampsia/eclampsia, extrauterine infection, severe maternal conditions, fetal anomaly and IUGR as clinical phenotypes with preterm births $(\mathrm{p}<0.05)$. The result also showed that there was a positive correlation of antepartum stillbirth with preterm birth and was statistically significant $(r=0.195, p=0.009)$. However, multiple gestation and APH/early pregnancy bleeding showed low correlation with preterm births but were not statistically significant $(\mathrm{p}>0.05)$ as shown in table 10 .

Table 10: Bivariate analysis of Clinical phenotypes and Preterm births

\begin{tabular}{lll}
\hline Clinical phenotypes & Pearson Correlation & Results \\
\hline Preeclampsia/Eclampsia & Pearson Correlation (r) & $-.155^{*}$ \\
& Sig. (2-tailed) $(\mathrm{p})$ & $\mathbf{0 . 0 3 9}$ \\
Extrauterine infections & $\mathrm{N}$ & 178 \\
& Pearson Correlation (r) & $-.215^{* *}$ \\
Severe maternal conditions & Sig. (2-tailed) (p) & $\mathbf{0 . 0 0 4}$ \\
& $\mathrm{N}$ & 178 \\
& Pearson Correlation (r) & $-.273^{* *}$ \\
Multiple gestation & Sig. (2-tailed) (p) & $\mathbf{0 . 0 0 0}$ \\
& $\mathrm{N}$ & 178 \\
Fetal anomaly & Pearson Correlation (r) & 0.061 \\
& Sig. (2-tailed) (p) & 0.416 \\
& $\mathrm{~N}$ & 178 \\
& Pearson Correlation (r) & $-.202^{*}$ \\
\hline
\end{tabular}


International Journal of Current Aspects, Volume 3, Issue III, 2019, PP 154-174, ISSN 2616-6976

iJCAB

\begin{tabular}{lll}
\hline & $\mathrm{N}$ & 178 \\
IUGR & Pearson Correlation (r) & $-.181^{*}$ \\
& Sig. (2-tailed) (p) & $\mathbf{0 . 0 1 6}$ \\
Antepartum stillbirth & $\mathrm{N}$ & 178 \\
& Pearson Correlation (r) & $.195^{* *}$ \\
& Sig. (2-tailed) (p) & $\mathbf{0 . 0 0 9}$ \\
APH/Early pregnancy bleeding & $\mathrm{N}$ & 178 \\
& Pearson Correlation (r) & 0.033 \\
& Sig. (2-tailed) (p) & 0.66 \\
& $\mathrm{~N}$ & 178 \\
\hline
\end{tabular}

* Correlation is significant at the 0.05 level (2-tailed).

** Correlation is significant at the 0.01 level (2-tailed).

Table 11 shows the Chi square goodness of fit test and Fisher's Exact test for the null hypothesis. Preeclampsia/eclampsia, extrauterine infections, severe maternal conditions, multiple gestations, fetal anomaly, IUGR, antepartum stillbirths and APH/early pregnancy bleeding as clinical phenotypes were found to be significantly associated with preterm births $(p<0.05)$. The null hypothesis was therefore rejected

Table 11: Test of Ho There is no significant association between clinical phenotypes and preterm birth

\begin{tabular}{|c|c|c|c|c|c|c|c|}
\hline \multirow[b]{2}{*}{ Clinical phenotypes } & & \multicolumn{2}{|c|}{ Preterm births } & \multirow[b]{2}{*}{$\begin{array}{l}32 \text { to }<34 \\
\text { weeks }\end{array}$} & \multirow[b]{2}{*}{$\begin{array}{l}34 \text { to }<37 \\
\text { weeks }\end{array}$} & \multirow[b]{2}{*}{$\begin{array}{l}\text { Total } \\
(n=178)\end{array}$} & \multirow[b]{2}{*}{$\begin{array}{l}\text { Significance } \\
\text { level }\end{array}$} \\
\hline & & $\begin{array}{l}<28 \\
\text { weeks }\end{array}$ & $\begin{array}{l}28 \text { to }<32 \\
\text { weeks }\end{array}$ & & & & \\
\hline \multirow[t]{2}{*}{ Preeclampsia/Eclampsia } & Yes & 2 & 4 & 17 & 16 & 39 & Fishers Exact \\
\hline & No & 21 & 35 & 32 & 51 & 139 & $p$ value $=0.017$ \\
\hline \multirow[t]{2}{*}{ Extrauterine infections } & Yes & 4 & 7 & 17 & 28 & 56 & Fishers Exact \\
\hline & No & 19 & 32 & 32 & 39 & 122 & $p$ value $=0.030$ \\
\hline \multirow[t]{2}{*}{$\begin{array}{l}\text { Severe maternal } \\
\text { conditions }\end{array}$} & Yes & 3 & 8 & 10 & 32 & 53 & Fishers Exact \\
\hline & No & 20 & 31 & 39 & 35 & 125 & $p$ value $=0.001$ \\
\hline \multirow[t]{2}{*}{ Multiple gestation } & Yes & 1 & 11 & 3 & 7 & 22 & Fishers Exact \\
\hline & No & 22 & 28 & 46 & 60 & 156 & $p$ value $=0.013$ \\
\hline \multirow[t]{2}{*}{ Fetal anomaly } & Yes & 0 & 0 & 1 & 7 & 8 & Fishers Exact \\
\hline & No & 23 & 39 & 48 & 60 & 170 & $p$ value $=0.048$ \\
\hline \multirow[t]{2}{*}{ IUGR } & Yes & 3 & 6 & 7 & 22 & 38 & Fishers Exact \\
\hline & No & 20 & 33 & 42 & 45 & 140 & $p$ value $=0.049$ \\
\hline \multirow[t]{2}{*}{ Antepartum stillbirth } & Yes & 8 & 13 & 8 & 10 & 39 & $\begin{array}{c}\chi^{2}=8.005 \\
\mathrm{df}=3\end{array}$ \\
\hline & No & 15 & 26 & 41 & 57 & 139 & $p$ value $=0.046$ \\
\hline \multirow[t]{2}{*}{$\begin{array}{l}\text { APH/Early pregnancy } \\
\text { bleeding }\end{array}$} & Yes & 4 & 18 & 20 & 18 & 60 & Fishers Exact \\
\hline & No & 19 & 21 & 29 & 49 & 118 & $p$ value $=0.025$ \\
\hline
\end{tabular}

\section{RECOMMENDATIONS}


Study concluded that all the clinical phenotypes (maternal, fetal and placental conditions); preeclampsia, extrauterine infections, severe maternal conditions, multiple gestations, fetal anomaly, IUGR, antepartum stillbirths and APH/early bleeding were significantly associated with preterm births. All clinical phenotypes except multiple gestations and APH/early bleeding were statistically significant with preterm births on bivariate analysis. Based on the results of this study, Barro's classifications system of clinical phenotypes should be used to phenotype all preterm births in JOOTRH. This will help in identification and understanding of the causes of preterm births and eventually aid in effective preventive intervention. Maternal, fetal and placental phenotypes identified in this study to be associated with preterm births underscore the need to identify these conditions early enough before or during pregnancy. This should be at the policy level both at the National and County Government of Kisumu, program managers at both government and Non-governmental organizations including PTBi-Kenya and other relevant stakeholders by adopting Barros' clinical phenotyping of preterm births as a strategy that aim to minimize or prevent the occurrence of preterm births which is known to be the major cause of neonatal mortality.

\section{REFERENCES}

Abdo, R. A., Endalemaw, T. B. \& Tesso, F. Y. (2016). Prevalence and Associated Factors of Adverse Birth Outcomes among Women Attended Maternity Ward at Negest Elene Mohammed Memorial General Hospital in Hosanna Town, SNNPR, Ethiopia. Journal of Womens Health Care, 5(4), 3-7.

Akintayo, A. A., Awoleke, J. O., Ogundare, E. O., Olatunya, O.S. and Aduloju, O. P. (2015). Preterm Births in a Resource Constrained Setting: Sociobiologic Risk Factors and Perinatal Outcomes. Ghana Medical Journal, 49(4).

Ananya, D., Subrat, P., Ahanthem, S. S., Sourabh, G. D. \& Bhanu, P. S. G. (2015). Preterm Birth: Analysis of Risk Factors and Neonatal Outcome. iMedPud Journal, 1(January 2013), $1-5$.

Barros, F. C., Papageorghiou, A. T., Victora, C. G., Noble, J. A., Pang, R., Iams, J., Ismail, L. C., Goldenberg, R. L., Lambert, A., Kramer, M. S., Carvalho, M., Conde-Agudelo, A., Jaffer, Y. A., Bertino, E., Gravett, M. G., Altman, D. G., Ohuma, E. et al. (2015). The Distribution of Clinical Phenotypes of Preterm Birth Syndrome: Implications for Prevention, 1-10.

Blencowe, H., Cousens, S., Chou, D., Oestergaard, M., Say, L., Moller, A., Kinney, M. \& Lawn, J. (2013). Born Too Soon: The global epidemiology of 15 million preterm births. Reproductive Health, 10(Suppl 1), 1-14.

Blencowe, H., Vos, T., Lee, A. C., Phillips, R., Lozano, R., Alvarado, M. R., Cousens, S. \& Lawn, J. E. (2013). Estimates of Neonatal Morbidities and Disabilities at Regional and Global Levels for 2010: Introduction, Methods Overview and Relevant Findings from the Global Burden of Disease Study, 74(december).

Bolarinwa, A. O. (2015). Principles and Methods of Validity and Reliability Testing of Quetionnaires Used in Social and Health Science Researches. Nigerian Postgraduate Medical Journal, 195-201.

Brown, H. K., Speechley, K. N., Macnab, J., Natale, R. \& Campbell, M. K. (2015). Maternal, Fetal and Placental Conditions Associated with Medically Indicated Late Preterm and Early Term Delivery: A Retrospective Study. An International Journal Of Obstetrics and Gynaecology.

Butali, A., Ezeaka, C., Ekhaguere, O., Weathers, N., Ladd, J., Fajulo, I., Esezobor, C., Makwe, C., Odusanya, B., Anorlu, R., Adeyemo, W., Iroha, E., Egri-Okwaji, M., Adejumo, P., 
Oyeneyin, L., Abiodun, M., Badejoko, B. \& Ryckman, K. (2016). Characteristics and Risk Factors of Preterm Births in a Tertiary Centre in Lagos, Nigeria. Pan African Medical Journal, $8688,1-8$.

Centre for Disease and Control/NCHS. (2015). Child Trends Data Bank: Preterm Births, Indicators on Children and Youth.

Chiabi, A., Mah, E. M., Mvondo, N., Nguefack, S., Mbuagbaw, L., Kamga, K. K., Zhang, S., Mboudou, E., Tchokoteu, P. F., \& Mbonda, E. (2013). Risk Factors for Premature Births: A Cross-Sectional Analysis of Hospital Records in a Cameroonian Health Facility. African Journal oF Reproductive Health, 17(December), 77-83.

County, K. (2013). Kisumu County First County Intergrated Plan 2013-2017: Towards a Globally Competitive and Prosperous Nation, (September 2013).

Delnord, M., Blondel, B., Prunet, C. \& Zeitlin, J. (2017). Are Risk Factors for Preterm and Early- term Live Singleton Birth the Same? A Population-based Study in France. BMJ Open, 1-10.

Field, D., Boyle, E., Draper, E., Evans, A., Johnson, S., Khan, K., Manktelow, B., Marlow, N., Petrou, S., Pritchard, C., Seaton, S. \& Smith, L. (2016). Programme Grants for Applied Research Towards Reducing Variations in Infant Mortality and Morbidity: A Populationbased Approach. National Institute for Health Research Journals, 4(1), 1- 204.

Garg, S., Kaur, T., Saran, A. S. \& Yadav, M. (2017). A study of Etiology and Outcome of Preterm Birth at a Tertiary Care Centre. International Journal of Reproduction, Contraception, Obstetrics and Gynecology, 6(10), 4488-4491.

Gebreslasie, K. (2016). Preterm Birth and Associated Factors among Mothers Who Gave Birth in Gondar Town Health Institutions. Open Access Journal, 2016, $1-6$.

Hidayat, Z. Z., Ajiz, E. A. \& Krisnadi, S. R. (2016). Risk Factors Associated with Preterm Birth at Hasan Sadikin General Hospital in 2015. Open Journal of Obstetric and Gynecology, 6(December), 798-806.

Hirst, J. E., Villar, J., Victora, C. G., Papageorghiou, A. T., Finkton, D., Barros, F. C., Gravett, M. G., Giuliani, F., Purwar, M., Fredrick, I. O., Pang, R., Ismail, L. C., Lambert, A., Stones, W., Jaffer, Y. A., Altman, D. G., Noble, J. A., Ohuma, E. , Z. A. (2016). The Antepartum Stillbirth Syndrome: Risk Factors and Pregnancy Conditions Identified from the INTERGROWTH-21st Project. An International Journal of Obstetrics and Gynaecology, (November), 1-9.

Ibiebele, I., Coory, M., Smith, G. C. S., Boyle, F. M., Vlack, S., Middleton, P., Roe, Y. \& Flenady, V. (2017). Gestational Age Specific Stillbirth Risk Among Indigenous and NonIndigenous Women in Queensland, Australia: A Population Based Study. BMC Pregnancy \& Childbirth, (March), $0-8$.

Ibrahimou, B., Anozie, C., Cruz, C. D. \& Salihu, H. (2015). Previous Preterm Birth and Current Maternal Complications as a Risk Factor of Subsequent Stillbirth. American Journal of Epidemiology, 2015, 1-7.

Iyoke, C. A., Lawani, E. C., Ezugwu, E. C., Ilechukwu, G., Nkwo, P. O., Mba, S. G. \& Asinobi, I. N. (2014). Prevalence and Perinatal Mortality Associated with Preterm Births in a Tertiary Medical Center in South East Nigeria. International Journal of Women's Health, 881-888.

Karegoudar, D., Prabhu, A., Amgain, K. \& Dhital, M. (2014). Perinatal Outcome and Associated Maternal Co-morbid conditions in late Preterm Births - A Prospective study at Kles Dr . 
Prabhakar Kore Hospital. International Journal of Current Microbiology and Applied Sciences, 3(6), 865-875.

Kieny, M.-P. (2015). The Sustainable Development Goals: The place of Health in the Post-2015 Agenda; Goals, Targets, indicators from MDG TO SDG.

KNBS. (2014). Kenya Demographic and Health Survey: Key indicators, 1-76.

KNBS. (2015). Kenya Demographic and Health Survey: 2014 Key Findings, 1- 86.

Kramer, M. S., Papageorghiou, A., Culhane, J., Bhutta, Z., Goldenberg, R. L., Gravett, M., Iams, J. D.Conde-agudelo, A., Waller, S., Barros, F., Knight, H. \& Villar, J. (2012). Challenges in Defining and Classifying the Preterm Birth Syndrome. American Journal of Obstetrics \& Gynecology, 206(2), 108-112.

Liu, L., Oza, S., Hogan, D., Chu, Y., Perin, J., Zhu, J., Lawn, J. E., Cousens, S., Mathers, C. \& Black, R. E. (2016). Global, Regional and National Causes of Under-5 Mortality in 200015: An Updated Systematic Analysis with Implications for the Sustainable Development Goals. The Lancet, 388(10063), 3027-3035.

Lloyd G. L. (2013). National Mortality in South Africa: How are we doing and can we do better? The South African Medical Journal, 23- 67.

Lu, L., Qu, Y., Tang, J., Chen, D. \& Mu, D. (2015). Risk Factors Associated with Late Preterm Births in the Underdeveloped Region of China: A Cohort Study and systematic review. Taiwanese Journal of Obstetrics \& Gynaecology, 54, 647- 653.

Mahapula, F. A., Kumpuni, K., Mlay, J. P. \&, \& Mrema, T. F. (2016). Risk Factors Associated with Pre-term Birth in Dar es Salaam, Tanzania: A Case-control Study. Tanzania Journal of Health Research, 18(1), 1-8.

Ministry of Health, K. (2016). Scaling Up Effective Interventions in Maternal and Newborn Health: Reducing Maternal and Neonatal Mortality in Kenya. An Implementation Plan fro the Period 2016-2018.

Mitao, M., Philemon, R., Obure, J., Mmbaga, B. T., Msuya, S. \& Mahande, M. J. (2016). Risk Factors and Adverse Perinatal Outcome Associated with Low Birth Weight in Northern Tanzania: A Registry-Based Retrospective Cohort Study. Asian Pacific Journal of Reproduction, 5(1), 75-79.

Mugenda, O. M., \& Mugenda, A. G. (2003). Research Methods: Qualitative and Quantitative Approaches. Nairobi: Act Press.

Neiger, R. (2017). Long-Term Effects of Pregnancy Complications on Maternal Health: A Review. Journal of Clinical Medicine, 6(76), 5.

Ntiloudi, D., Zegkos, T., Bazmpani, M. A., Parcharidou, D., Panagiotidis, T., Hadjimiltiades, S., Karvounis, H. \& Giannakoulas, G. (2017). Pregnancy Outcome in Women with Congenital Heart Disease: A single-center Experience. Hellenic Journal of Cardiology, 1-5.

Ooko, S. (2014, November). Rise in Preterm Births Threat to Child Health in Kenya. Nation Media Group. Nairobi.

Ozer, E. (2013). Placenta in Preterm Birth. Open Access Journal, 110- 112.

Parets, S. E., Bedient, C. E., Menon, R. \& Smith, A. K. (2014). Preterm Birth and Its Long-Term Effects: Methylation to Mechanisms. Open Access Journal, 498-513.

Passini Jr, R., Cecatti, J. G., Lajos, G. J., Tedesco, R. P., Nomura, M. L., Dias, T. Z., Haddad, S. M., Rehder, P. M., Pacagnella, R. C., Costa, M. L. \& Sousa, M. H. (2014). Brazilian Multicentre Study on Preterm Birth (EMIP): Prevalence and Factors Associated with Spontaneous Preterm Birth. PLoS One, 9(10). 
Pignotti, M. S., \& Donzelli, G. (2015). Preterm Babies at a Glance. Journal of Clinical Neonatology, vol. 4(2), 1-7.

Rao, C. R., Ruiter, L. E. E., Bhat, P., Kamath, V., Kamath, A. \& Bhat, V. (2014). A CaseControl Study on Risk Factors for Preterm Deliveries in a Secondary Care Hospital, Southern India. Obstetrics and Gynecology International, 2014, 1- 5.

Rosseto, R., Melo, E. C., Falavina, L. P. \& Mathias, T. A. de F. (2015). The Growing Trend of Moderate Preterm Births: An Ecoogical Study in One Region of Brazil. PLoS One, 1, 1-11.

Shah, R., Mullany, L. C., Darmstadt, G. L., Mannan, I., Rahman, S. M., Talukder, R. R., Applegate, J. A., Begum, N., Mitra, D., El Arifeen, S. \& Baqui, A. H. (2014). Incidence and risk factors of preterm birth in a rural Bangladeshi cohort. BMC Pediatrics, 1-11.

Shapiro-Mendoza, C. K., Tomashek, K. M., Kotelchuck, M., Barfield, W., Nannini, A., Weiss, J. \& Declercq, E. (2014). Effect of Late-Preterm Birth and Maternal Medical Conditions on Newborn Morbidity Risk. Open Access Journal, 121(2), 1- 12.

Slyker, J. A., Patterson, J., Gwen, A., Richardson, B. A., Maleche-Obimbo, E., Bosire, R., Mbori-Ngacha, D., Farquhar, C. \& John-Stewart, G. (2014). Correlates and Outcomes of Preterm Birth, Low Birth Weight and Small for Gestational Age in HIV-exposed Uninfected Infants. BMC Pregnancy \& Childbirth, 14(7), 1- 10.

Temu, T. B., Masenga, G., Obure, J., Mosha, D. \& Mahande, M. J. (2016). Maternal and Obstetric Risk Fatcors Associated with Preterm Delivery at a Referral Hospital in NorthernEastern Tanzania. Asian Pacific Journal of Reproduction, 5(5), 365-370.

United State International Agency for Development. (2015). Kenya: Profile of Preterm and Low Birth Weight Prevention and Care, 10-12.

Van den Broek, N. R., Jean-Baptiste, R. \& Neilson, J. P. (2014). Factors Associated with Preterm, Early Preterm and Late Preterm Birth in Malawi. PLoS One, 9(3), 1- 8.

Wagura, P. M. (2014). Prevalence and Factors Associated with Preterm Birth at Kenyatta National Hospital. A Dissertation for Mmed (Paeds) Thesis 2014.

WHO. (2015a). Global Health Observatory ( GHO ) data Under-five mortality: Child Mortality and Causes of Death, 2015-2016.

WHO. (2015b). Preterm Birth, (Fact Sheet No. 363).

WHO. (2017). Preterm birth: Fact sheet Updated November 2017.

Yi, S. W., Han, Y. J. \& Ohrr, H. (2013). Anemia Before Pregnancy and Risk of Preterm Birth, Low Birth Weight and Small-for-Gestational-Age Birth in Korean Women. European Journal of Clinical Nutrition, 67(February), 337-342.

You, D., Hug, L., Ejdemyr, S. and Beise, J. (2015). Levels and Trends in Child Mortality: Report 2015 Estimates Development by the UN Inter-agency Group for Child Mortality Estimation. Open Access Journal, 23- 42.

This is an open-access article published and distributed under the terms and conditions of the $(c))_{E Y}$ Creative Commons Attribution 4.0 International License of United States unless otherwise stated. Access, citation and distribution of this article is allowed with full recognition of the authors and the source.

Authors seeking to publish with an International Peer Reviewed Journal should consider www.ijcab.org by writing to the Editor at editor@ijcab.org. 